\title{
Complete encapsulation of a leadless cardiac pacemaker
}

\author{
Alexander Kypta ${ }^{1} \cdot$ Hermann Blessberger $^{1} \cdot$ Michael Lichtenauer $^{2}$. \\ Clemens Steinwender ${ }^{1}$
}

Received: 14 September 2015/Accepted: 15 October 2015/Published online: 22 October 2015

(C) Springer-Verlag Berlin Heidelberg 2015

\section{Sirs:}

An 82-year-old patient with permanent atrial fibrillation and symptomatic bradycardia had received a leadless cardiac pacemaker (LCP, Micra ${ }^{\mathrm{TM}}$, Medtronic Inc., Minneapolis, MN, USA) at our institution. The implant procedure and further clinical course were uneventful. One year after implantation the patient died due to respiratory failure caused by severe pulmonary fibrosis. During autopsy the device was found to be located at the right ventricular apexwhere it had been initially implanted-fixed with its anchor tines. It could be observed that the LCP was completely covered by a semitransparent tissue layer and adherent to the adjacent papillary muscle (Fig. 1).

Leadless pacemakers were recently introduced to overcome pocket- and lead-related complications of conventional pacing systems.

The Micra ${ }^{\mathrm{TM}}$ is a single-chamber LCP that is delivered to the right ventricular apex via a catheter through the femoral vein. Its implantation characteristics and early performance has been recently published [1].

However, long-term experience, especially regarding the amount of encapsulation of the LCP systems, is still missing. Further studies on this topic are essential as all current concepts for LCP replacement are based on interventional extraction techniques that require at least a bare tail of the device.

Alexander Kypta

Alexander.kypta@gmail.com

1 Department of Cardiology, Linz General Hospital, Johannes Kepler University School of Medicine, Linz, Austria

2 Department of Cardiology, Clinic of Internal Medicine II, Paracelsus Medical University of Salzburg, Salzburg, Austria

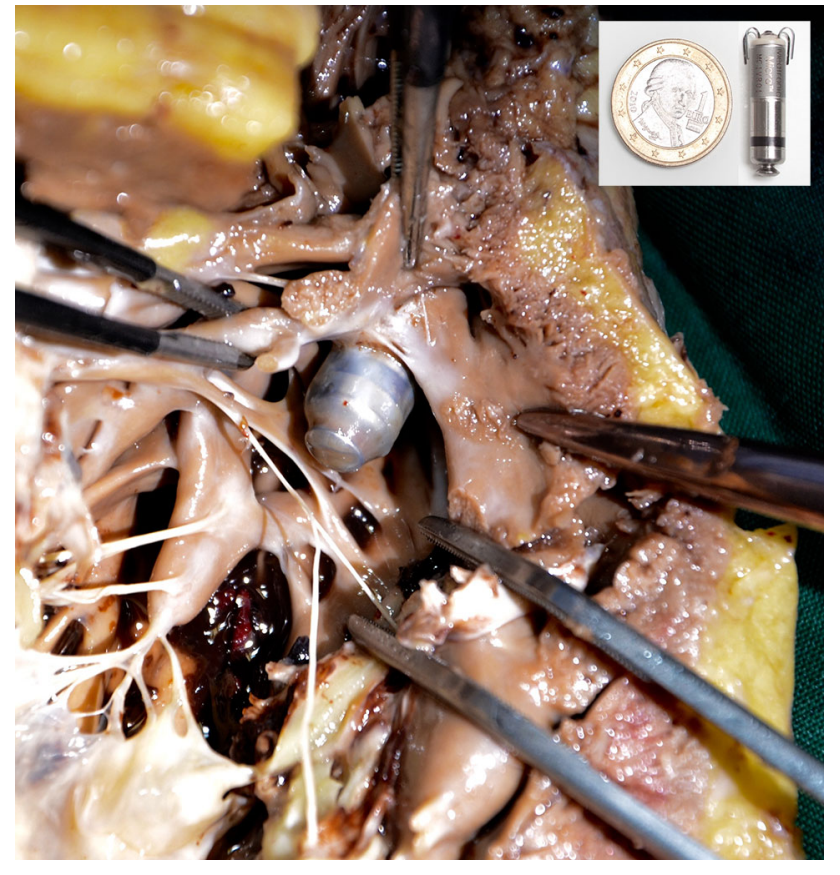

Fig. 1 Leadless cardiac pacemaker in the apex of the right ventricle totally encapsulated

Compliance with ethical standards

Conflict of interest None.

\section{Reference}

1. Ritter P, Duray GZ, Steinwender C, Soejima K, Omar R, Mont L, Boersma LV, Knops RE, Chinitz L, Zhang S, Narasimhan C, Hummel J, Lloyd M, Simmers TA, Voigt A, Laager V, Stromberg K, Bonner MD, Sheldon TJ, Reynolds D, Micra Transcatheter Pacing Study Group (2015) Early performance of a miniaturized leadless cardiac pacemaker: the Micra Transcatheter Pacing Study. Eur Heart J 36:2510-2519 